\title{
INTRODUCTION TO THE FORUM KRITIKA ON FOOD TRANSFORMATIONS ${ }^{1}$
}

\author{
Simon C. Estok \\ Sichuan University \\ Sungkyunkwan University \\ estok@skku.edu
}

\begin{abstract}
"Introduction to the Forum Kritika on Food Transformations" briefly introduces the parameters within which the seven articles of the Forum explore the topic of food transformations. In addition to offering brief summaries of the articles, the "Introduction" explains the range of discussions (from Shakespeare to the present and beyond) and the logic of the organization of the Forum.
\end{abstract}

\section{Keywords}

climate change and food; food and the Global South; food transformations; GMOs

\section{About the Author}

Simon C. Estok currently holds the award of Foreign Expert of the Double First Class Discipline Cluster (2018-2021) at Sichuan University and is Full Professor and Senior Research Fellow at Sungkyunkwan University (South Korea's first and oldest university). Dr. Estok teaches literary theory, ecocriticism, and Shakespearean literature. His award-winning book Ecocriticism and Shakespeare: Reading Ecophobia appeared in 2011 (Palgrave Macmillan, reprinted 2014), and he is co-editor of three books: Landscape, Seascape, and the Eco-Spatial Imagination (Routledge, 2016), International Perspectives in Feminist Ecocriticism (Routledge, 2013), and East Asian Ecocriticisms (Macmillan, 2013). His latest book is the much anticipated The Ecophobia Hypothesis (Routledge, 2018). Estok has published extensively on ecocriticism and Shakespeare in journals such as PMLA, Mosaic, Configurations, English Studies in Canada, and others. 
There is a lot of nonsense in discussions about food, from "fakelore masquerading as folklore" (Adams 5) to politics posturing as science; from profit impersonating social betterment to outright lies counterfeiting truth. There is a profound urgency to address, both theoretically and practically, matters about food. As we leap and bound down the road of climate change toward uncertain (but certainly dangerous) futures, with our eyes fixed on the dramatic losses of human life that will occur in the years and decades to follow, it is absolutely vital to understand that it will be starvation more than floodings, more than heat strokes, more than wild fires, more than freezing temperatures that will take the greatest toll on humanity. Without our grains and legumes, our fruits and our nuts, our bees and our flowers, we will face staggering losses. It is coming. The circularity of the problem is ironic. It is food production methods that have been one of the main contributors to climate change; ironically, it is climate change that will halt our very abilities to produce food. The industrial livestock industry in particular has been the most obvious culprit producing enormous quantities of greenhouse gases (primarily carbon dioxide and methane), and as Greta Gaard has recently observed, "the ecological and human toll of industrialized human agriculture is no longer debated" (27). The transformations of animals into flesh factories and food into what food critic Michael Pollan has called "foodlike substances" (1) raise ethical, environmental, and health issues. The articles in this Forum Kritika on Food Transformations theorize about relationships between food justice and environmental justice, offer comments on the impacts of transnational food systems on the Global South, and evaluate the implications of current and foreseeable future artificial food-like substances, GMOs, and synthetic hormones.

There is no question that food these days is rapidly transforming. Pollan has noted that the foods much of the world eats today would simply be unrecognizable to our great grandparents. But why should these food transformations concern us, and why now? Part of the answer is in the fact that food is deeply enmeshed in everything that we do. Canadian ecocritic Susie O'Brien has recently explained in an interview in ARIEL that "food is a rich site through which to think about a number of things: environment, colonialism, culture, affect, subjectivity, among others" (Szabo-Jones 207). There is an urgency to theorizing about food also because hunger is so seriously at odds with the promises of industrial agriculture. Indeed, according to Vandana Shiva, "industrial agriculture has not produced more food. It has destroyed diverse sources of food, and it has stolen food from other species to bring larger quantities of specific commodities to the market, using huge quantities of fossil fuels and water and toxic chemicals in the process" (12). 
The logic of the organization of the articles in this Forum Kritika on Food Transformations is to move backward from several centuries in the future, to the present, then to several centuries in the past, and finally to return in the end to the present with a brief film review.

The first two articles of this Forum Kritika on Food Transformations investigate aspects of Paolo Bacigalupi’s The Windup Girl. Jungyoun Kim's “The Problematic Representations of the Orient, Women, and Food Transformations in Paolo Bacigalupi's The Windup Girl" tackles questions about the racial and gender politics of representation and the Orientalist and sexist stereotypes that seem to be involved in the novel's critique of genetic modification and food transformation technologies. Kim argues that it matters who speaks for whom and that although Bacigalupi effectively exposes the dangers of mass produced genetically modified food and the transformation of food into industrial products by Western-based multinational agri-corporations, setting the novel in Asia and reproducing Western fantasies and stereotypes of Asia seem to run counter to the overall thematic thrust of the novel. While the novel does, as Kim argues, succeed in showing how "the dangerous and uncertain future of food transformations is entangled with racial and gender matters in the novel," the novel is in some important ways compromised by the stereotypes it deploys.

Young-Hyun Lee takes a rather different focus on The Windup Girl in her "Food Transformation Technology in Paolo Bacigalupi's The Windup Girl and What it Means for Us," arguing that food transformation technologies are deeply paradoxical, potentially offering both redemption and apocalypse. Lee argues that there are a great many potential problems with genetically modified foods, problems that are quickening our downfall and that find acute expression in The Windup Girl. As Lee rightly explains, climate change is creating urgent food issues in our own time, and GMO technologies are one very important attempt to solve these problems. It is the very reason why the world has contributed the 860,000 varieties of seeds to the Norwegian Svalbard Seed Vault. Climate change is simply happening at a rate too rapid for plants to adapt. Our self-appointed role is to help them to adapt faster-and, indeed, it seems that we really do not have much choice: it is either GMOs or starvation. It is a bleak scenario, but it is coming. Lee deftly shows how Bacigalupi's futuristic novel suggests a possible-perhaps even probable-trajectory point in the $23^{\text {rd }}$ century of where our meddling with foods may take us. It is not a pretty place. GM technologies, ostensibly developed to produce more food and solve food shortage problems have unknown side effects, both in terms of ecology and in terms of human health, in our own world and in the fictional world of The Windup Girl. Driven, as Lee explains, by multinational corporations (both in our world and in The 
Windup Girl), these food transformation technologies may already be out of our control and could lead to the demise of human civilization.

In many ways thematically similar to Bacigalupi's The Windup Girl, Margaret Atwood's Oryx and Crake is the subject of the next article in the volume. Chao Xie's "GM Foods, Power, and Globalization in Oryx and Crake" offers a series of close readings to show that GM foods in the novel have a material agency with which the characters must reckon. The effects of this agency on culture and nature are both local and global. Xie shows that "GM food raises important questions on issues about power, race, gender, and nation and becomes a crucial semiotics of environmental ethics in the Anthropocene time."

Iris Ralph's reading of two Australian works of literature brings us back to the present. Ralph's analysis of Merlinda Bobis's cli-fi novel Locust Girl and Evie Wyld's post-pastoral fiction All the Birds Singing draws important "connections between the transformation of food in the last two hundred and thirty years and the areas of inquiry of animal studies, indigenous studies, ecocriticism, ecofeminism, and environmental history." Among the matters Ralph covers are the development of the commercial kangaroo-meat industry, desertification that results from industrial agriculture, and the depletion of grain-belt biodiversity. Firmly within the Australian pastoral tradition, Bobis and Wyld critique the transformation of food practices and Australia's cattle industry and offer texts that show the importance of literary food studies for real world material practices.

Sophie Christman's “Alt-Burger: Transforming Populist Food Systems" passionately interrogates the "problematic nexus between the industrial livestock industry, US food system policies, and American propagandist literature." Building on the work of Carol J. Adams and her recent study of "the burger," Christman reviews the unsustainability of beef in her discussion of state-sponsored beef propaganda, provocatively (and convincingly) likening the meat industry to pederasty. Building on theories I develop in The Ecophobia Hypothesis about how "the very concept of the fully industrialized nation has at its core an ethics of meat" (92), Christman describes the practice of meat eating as a "normalized form of ecophobia," a violent transformation of flesh into food that depends on and reproduces indifference toward animals-and, indeed, toward the health of the planet. Christman finishes with a discussion of American comics and their paradoxical functions of both apparatus of the state and vehicles of consciousness-raising about how rapidly transforming industrial food systems impact climate change.

My own article takes the conversation back several hundred years to Shakespeare. "Timon of Athens, Food Transformations, and the World as 
Confectionary" looks at food as a transformative material on the Shakespearean stage. Often evoking intense visceral responses, food is and perhaps always has been a hot topic. Even environmentally conscious people become tetchy, for instance, when confronted with the consequences of their food choices. ${ }^{2}$ On Shakespeare's stage, too, food evokes strong responses, perhaps nowhere more clearly than in Timon of Athens. As I explain in detail, "Shakespeare's food embodies the inverse relationship between nationalism on the one hand and the increasingly global reach of the British imperial appetite on the other, a conflict that continues to press upon the present." Very different than the written play, the performed play is far more fluid and contextual, and "to engage with the questions raised by the global-sourcing/local-demand conflict of Shakespeare's food through performance-and to do so from geographically, temporally, and ideologically situated positions-exposes the radically transformative and deterritorializing potentials embedded in food." Indeed, the flux and variety of possibilities make it difficult to talk definitively about Shakespeare's food transformations, but it is precisely such flux and variability that define reality.

Of all of the subjects covered in this Forum Kritika, perhaps nowhere is the flux and variability of life more present than in the film Peina Zhuang reviews. Zhuang takes us back to the present with her "Film Review: An Analysis of Food Narrative in the Indian Film Lunchbox." Zhuang explains how the transformations brought about by modernity and city life in current-day Bombay produce a lunch delivery system that both safeguards food traditions by preserving the traditional menu while at the same time throwing into disarray social organization, caste requirements, and family relations, yet at the same time preserving iniquitous gender relations in India.

The motivation behind this Forum Kritika was to provide a medium through with to discuss food transformations through analyses of literary works, to come to understandings of the ways in which the practices of corporate capitalism and the pursuit of profit in the American food industry are neither viable nor productive of sustainable food sources, and to gauge and discuss the impacts of these practices on the Global South. The parameters were wide, asking about relationships between ecophobia, food, and rampant nationalism, and how cultural and national identities that cohere in food systems come under threat when those food systems are dismantled; how we can theorize about the waste associated with food production, and how these theoretical understandings cohere within the context of current debates about the definitional reach of the term Anthropocene; how we can theorize about relationships between food justice and environmental justice; what the impacts are of transnational food systems on the Global South; and how important artificial food-like substances, GMOs, and synthetic hormones are and why. The discussions of 
food transformations that follow have offered many answers, but the one that stands out most is that everyone eats every day, and the way that we can have the most immediate impact on climate change is in how we choose to eat. Yet, while the authors below offer many answers, many more questions perhaps have arisen. 


\section{Notes}

1. This article was funded by the double-first class discipline cluster "The Chinese Language and Literature and the Global Dissemination of Chinese Culture," Sichuan University, China.

2. Harold Fromm-one of the editors of the field-initiating Ecocriticism Readeroffers a particularly shocking example of intense response to veganism and argues vigorously in The Chronicle of Higher Education against vegans. In his rant, he speculates that vegans "are enlisted in an open-ended but futile metaphysic of virtue and self-blamelessness that pretends to escape from the conditions of life itself" ("Vegans"). There are many people (vegans and non-vegans) who would object to this kind of characterization of what veganism is all about-at least judging from the 95 blog responses that were posted online. Fromm argues from very mistaken notions about veganism and vegans that "behind their beliefs is the hopeless longing for innocence." I deal with the Fromm rant extensively in The Ecophobia Hypothesis (99-101), from which I have drawn much of this endnote. 


\section{Works Cited}

Adams, Carol J. Burger. Bloomsbury, 2018.

Estok, Simon C. The Ecophobia Hypothesis. Routledge, 2018.

Fromm, Harold. "Vegans and the Quest for Purity." The Chronicle of Higher Education, 4 July 2010. www.chronicle.com/article/Vegansthe-Quest-for/6609o/?sid=cr.

Gaard, Greta. "Ecofeminism and Climate Change." Women's Studies International Forum, vol. 49, 2015, pp. 20-33.

Pollan, Michael. In Defense of Food: An Eater's Manifesto. Penguin, 2008.

Shiva, Vandana. Stolen Harvest: The Hijacking of the Global Food Supply. Zed Books, 2000.

Szabo-Jones, Lisa. “An Interview with Susie O’Brien Conducted via Email between February 3 and March 1, 2014." ARIEL: A Review of International English Literature, vol. 44, no. 4, October 2013, pp. 205-17. 